Journal of Social Sciences 2 (4): 93-99, 2006

ISSN 1549-3652

(C) 2006 Science Publications

\title{
How Youth in India and Lebanon Rate their Intelligence
}

\author{
${ }^{1}$ Ramzi Nasser and ${ }^{2}$ Sushila Singhal, \\ ${ }^{1}$ Notre Dame University, P.O.Box 72, Zouk Mosbeh, Lebanon \\ ${ }^{2}$ Jawaharlal Nehru University, New Delhi, India
}

\begin{abstract}
A sample of 648 Lebanese and 252 Indian students estimated their intelligences based on Gardner's 10 multiple intelligence. Males rated higher their body kinesthetic and religious dimension (spiritual) while females rated higher their verbal and intra-personal estimates of intelligence. Using the educational level of the parent, no significant correlation with self-estimates of intelligence for each of the national samples was reported. Differences appeared between Indian and Lebanese samples on the cognitive components of intelligences, namely, verbal, spatial and logical abilities. ANOVA results showed that a higher logical component higher than their female counterparts and Indian males and females.
\end{abstract}

Key words: Self-estimates of intelligence, sex and cross-cultural difference

\section{INTRODUCTION}

The literature on the lay estimates of intelligence spans over more than three decades and is considerable in size. Many studies had been confined to measuring overall intelligence or ' $\mathrm{g}{ }^{,[1-4]}$ until the introduction of Gardner's multiple intelligence theory that opened new vistas for researchers. Gardner ${ }^{[5,6]}$ argued that despite the success of standard IQ in predicting ability in school subjects, it did not highlight the potential/competence of an individual in particular fields of expertise. Gardner's theory of multiple intelligences identifies eight subtypes of intelligence that every normal individual should develop to some degree (linguistic, logical/mathematical, spatial, interpersonal, intrapersonal, musical, bodily-kinesthetic and naturalistic ${ }^{[5]}$. Later, with the merger of cerebral research and cognitive psychology, specific ontological tasks were associated with intelligence. Blyth and Gardner $^{[7]}$ and Gardner ${ }^{[6]}$ came up with two other debatable dimensions to multiple intelligences those being existential and spiritual.

A number of cross-national studies on selfassessment have distinguished between the type of intelligence measures used to self-estimate one's intelligence. The general "g" measure score has been generally higher than scores obtained using Gardner's multiple intelligences. While the former includes kinesthetic or musical abilities which tend to increase intelligence in developed nations; however, in transition countries where basic educational resources are scarce, these types of abilities may act as source of lower estimates of multiple intelligences ${ }^{[8]}$. In addition, it is argued that the higher the cognitive components of verbal and logical ability among males could be attributable to the lower female score which increases the overall aggregate score on general intelligences ${ }^{[9,10]}$.
As different intelligences evolve through specific cerebral functioning, intelligence according to Howard Gardner is not limited to verbal and logical abilities but viewed as an all-encompassing characteristic dealing with behavior, affect and cognition.

Sex differences: Studies suggest small, stable and significant sex differences in self-estimates of intelligence and more so on specific skills. Interestingly, little has changed in that direction over the years. Beginning with Anastasi ${ }^{[9]}$, Tyler ${ }^{[10]}$ and Maccoby ${ }^{[11]}$ agreed that males performance was better than females on tests of mathematical reasoning and that the male advantage increased with age. It is also observed that within societies characterized by kinship and patriarchal systems, distinct bias prevails towards higher male self-estimates on the mathematical components and kinesthetic abilities. Hogan ${ }^{[4]}$, for instance, reported that in a review of 11 studies more than half of the studies demonstrated significant differences between male and female self-estimates of IQ levels. Hogan argued that women tend to perceive themselves as less intelligent than men because women may not be regarded by society as intelligent as men. In a study of Scottish students, it was noted that women underestimated their intelligence compared to $\mathrm{men}^{[12]}$. It was also suggested that male self-estimates of intelligence was higher than females on spatial and logical components. Even the estimates of parental, grandparental and sibling IQ favored fathers as more intelligent than mothers ${ }^{[13]}$, grandfathers more intelligent than grandmothers ${ }^{[2]}$ and brothers more intelligent than sisters ${ }^{[14]}$.

In a further review of sex differences on estimates of intelligence, Bennett ${ }^{[1]}$ reported that male respondents self-estimated their IQ higher than females, but males did not attribute to themselves higher levels

Corresponding Author: $\quad$ Ramzi Nasser, Notre Dame University, P.O.Box 72, Zouk Mosbeh, Lebanon 
of interpersonal intelligence any more than females. Referring to cognitive abilities Halpern ${ }^{[15]}$ wrote, males on average score higher on tasks that require transformations in visual-spatial, working memory, motor skills involved in aiming, spatial-temporal and fluid reasoning, especially in abstract mathematical and scientific domains, whereas males performed better than females on the mathematical reasoning and spatial tasks and females were more successful at tasks requiring the use of language, arithmetical evaluation and manual precision ${ }^{[16,17]}$. Halpern ${ }^{[15]}$ suggested that cognitive abilities are correlated with self-estimates. Male high self-estimates can be found for instance, among British fathers, estimated their overall IQ and the logical and spatial components higher than the mothers and both parents rated their sons more intelligent than daughters ${ }^{[18,19]}$. In addition, Furnham ${ }^{[19]}$ speculated that the mathematical and spatial intelligence of $\operatorname{Gardne}^{[5]}$ lie at the heart of most people's conception of intelligence. Lay people may conflate mathematical and spatial intelligence with overall intelligence, leading to overall sex differences in self-estimates of intelligence. Moreover, Furnham and Mkhize $^{[20]}$, in their interviews of Zulu mothers, noted that the best predictor of self-estimates of their children's IQ were mathematical and spatial intelligence. Zulu mothers showed few significant differences in their estimates of sons and daughters overall measure of multiple intelligences. Generally, males are attuned to self-estimate their intelligence higher than females, particularly on mathematical components of intelligence as these include spatial and logical components.

International differences in the estimates of intelligence: Several international studies have explored the concept of intelligence across Europe ${ }^{[21]}$; United States $^{[22]}$; Africa ${ }^{[23]}$, Lebanon ${ }^{[24]}$ and Asia ${ }^{[25]}$. These studies demonstrated cross-cultural differences in the type of conception of intelligence. For instance, Japanese college students considered social attitudes as being sympathetic, modest and seeing another's point of view as a characteristic of intelligence ${ }^{[25]}$. On the other hand Africans perceive intelligent persons as those who cooperate socially ${ }^{[26]}$. Furnham and Baguma $^{[27]}$ found a significant national difference between American and Africans on the mean score for Gardner's ${ }^{[6]}$ seven multiple intelligences; White Americans reported a higher mean estimate on the logical and spatial component (mathematical) and musical and bodily kinesthetic (cultural), while Africans rated higher verbal IQ. Furnham et al. ${ }^{[28]}$ compared American, British and Japanese students on three factors that underlie Gardner's seven multiple intelligences. Males' self-estimates of intelligence were higher than those for females across cultures, where Americans gave the highest estimates followed by British and Japanese. Moreover, Furnham et al. ${ }^{[14]}$ explored estimates of intelligence between British, Hawaiian and Chinese Singaporeans. The British selfestimates of intelligence were higher than Hawaiians followed by Chinese Singaporeans. Only one study could be traced that compared the Middle Eastern and Western societies on estimates of intelligence. Significant differences in self-estimates of intelligence between British and Iranian students found that British students had higher estimates on the mathematical component but lower than Iranians on their spatial, musical and intrapersonal components ${ }^{[8]}$. In view of the cultural differences in sex role behavior and the Western cultural influence in the East, it is suggested that estimates of intelligence in non-Western societies have greater propensity to yield lower self-estimates and greater differences favoring males over females. In addition, the use of Gardner's additional intelligence types suggests that females are more inclined to rate themselves higher the non-masculine components of intelligence.

Purpose of the study: This study compares Indian and Lebanese university/college entering students on their estimates of intelligence. The study is significant in that it includes Gardner's multiple intelligences and measures of intelligence along social, bodily, metaphysical and academic aspects and compares students of Near East with those in the East. More specifically, this study compares students in Lebanese society, who have experienced more than 16 years of civil strife and foreign occupations ${ }^{[29]}$ with those in India, a relatively thriving democracy moving along the lines of modernity ${ }^{[30]}$. Lebanon is patriarchal, where the family structure and kinship networks are strong in identity formation and cognitive behaviors ${ }^{[31]}$. The patriarchal belief-system has legitimated further subjugation of women to an existing male-supremacist socio-political structure, which denies women's citizenship rights in a myriad of ways ${ }^{[32,33]}$. Similarly, in Indian society kinship structure and patriarchy continue to operate as two discriminatory practices against women (marriage system and economic value). It is not to deny that within the kinship-based patriarchal structure, women's position may be multidimensional ${ }^{[34]}$. Specifically, India has great diversity and distinct regional patterns ${ }^{[34]}$. The long standing regional divide between Southern and Northern parts of India and the differences among Lebanon's confessional groups and kinship behaviors suggest that differences can not be limited to gender differences but to other exogenous variables that could play a role.

Patriarchy and kinship along with economic and social stratification map women's place in a society. Families with high socio-economic status in the Arab World, women find greater autonomy to advance as professionals ${ }^{[35]}$ than others. Similarly in India, a high negative correlation between class and patriarchy suggests that women from higher socio-economic 
groups have greater autonomy in the work force ${ }^{[36]}$. No rigorous empirical tests have been undertaken to date to examine the possible relationship between socioeconomic status and estimates of intelligence, although Furnham $^{[37]}$ recognized that parental attentiveness, solicitousness, socioeconomic status and socio-cultural parenting have important influences on the way selfestimates of intelligence are made.

Furnham $^{[37]}$ and Furnham et al. ${ }^{[8]}$ suggest that the estimates of intelligence have become a key issue in educational assessment because of the rise of the educational attainment levels of these nations. In other words, children and youth are in much greater ratios to receive education substantially different than their illiterate parents and those younger groups would selfestimate their intelligence higher than their parents or grandparents. The main premise of this study is that in addition to cultural differences, parents' educational attainment level may be an important predictor of selfestimates of intelligence.

With the diverse findings on self-estimates of intelligence, a comparison between the Indian and Lebanese samples is significant from the perspective that wide gaps do exist between Eastern and Far Eastern countries on values, attitudes and norms. This research advances the proposition that because of strong kinship structures in both societies the sex differences between Lebanese and Indian self estimates of intelligence may throw up similar patterns not evident in studies on estimates of intelligence.

\section{MATERIALS AND METHODS}

Participants: The Lebanese sample consisted of 247 female and 401 males aged between 16 and 30 with a mean age of 18.2 years $(\mathrm{SD}=1.56)$. The Lebanese sample included entering university students to a private Catholic university that followed the American credit system of higher education. The university offered liberal arts, education, social sciences and the humanities programs as well as professional degrees in engineering, education and computer science. In order to limit the cross-cultural comparison to Lebanese and Indian college students, foreign participants were removed from the Lebanese sample. The Indian sample was composed of 110 females and 142 males with a mean age of about 18 years $(\mathrm{SD}=0.53)$ and an age range from 14 to 19 years. These Indian students came from schools with English as the medium of instruction and applied to the first year of university education. Indian as well as Lebanese respondents were entering into the degree programs in humanities and social sciences, science, commerce, engineering, medicine and dental science.

Subjects were given a questionnaire having two main sections. In one section, the questionnaire obtained background information; sex, age, perceived socio-economic class of the family and educational level of the mothers and fathers. The second part included an explanation of the normal curve through an illustration with a mean of 100 and one standard deviation of 15 IQ units. The normal distribution ranged on a continuum on the $\mathrm{X}$-axis from 55 to 145 . Prior to the administration of the questionnaire, respondents were briefed about the project and were told that no penalty would be levied if they did not respond to the questionnaire. In India, the school principals were approached to explain the research objectives and their permission to meet the students was obtained prior to the administration of the questionnaire. Respondents were asked to read the directions and respond to the questionnaire in a 30minute time-span.

\section{RESULTS}

Table 1: Correlation between parents' educational level and student rating on each of the samples

\begin{tabular}{lccc}
\hline & Lebanon & India & Overall Sample \\
\hline Verbal & -.03 & .12 & .05 \\
Logical & -.01 & .03 & .04 \\
Spatial & .03 & .09 & .07 \\
Musical & .06 & -.01 & .04 \\
Body Kinesthetic & -.01 & -.02 & -.00 \\
Inter-personal & -.01 & .05 & .03 \\
Intra-personal & -.02 & -.07 & -.05 \\
Existential & -.08 & .01 & -.04 \\
Spiritual & -.06 & .01 & -.00 \\
Naturalistic & -.06 & .03 & -.02 \\
\hline *two-tailed $\mathrm{p}<.05$ & & & \\
$* *$ two-tailed $\mathrm{p}<.001$ & & &
\end{tabular}

The first analyses present separate correlations between parents' educational level and respondents' self-estimates of intelligence for each national group. Table 1 presents the correlations between parents' level of education with each of the ten multiple intelligences. No significant association appeared between the ratings and educational level. A $2 \times 2$ factorial ANOVA of nationality (Indian/Lebanese) by sex (male/female) on the self estimates of intelligence was run. The ANOVA results showed significant differences between males and females on four aspects of Gardner's 10 multipleintelligences; verbal, body kinesthetic, intra-personal and the naturalistic dimension. In the addition to the post-hoc analysis Table 2 presents the means of the nationality by gender. Table 3 presents the F-values for main and interaction effects. Females had significantly higher self-estimates than males on the verbal and intrapersonal components of Gardner's multiple intelligences; whereas, male students had higher estimates on the body-kinesthetic and the naturalistic dimensions (Table 2). Non-significant differences by males on logical, spatial, existential and naturalistic 


\begin{tabular}{|c|c|c|c|c|c|c|c|}
\hline & Sex & $\begin{array}{l}\text { Post- } \\
\text { Hocs }\end{array}$ & Nationality & Post-Hocs & Mean & Std. Deviation & $\mathrm{N}$ \\
\hline \multirow[t]{4}{*}{ Verbal } & \multirow[t]{2}{*}{ Male } & $\alpha$ & Lebanese & $\mathrm{A}$ & 106.59 & 11.99 & 299 \\
\hline & & $\alpha$ & Indian & B & 101.97 & 14.40 & 142 \\
\hline & \multirow[t]{2}{*}{ female } & $\beta$ & Lebanese & A & 111.17 & 12.15 & 192 \\
\hline & & $\beta$ & Indian & B & 106.60 & 15.35 & 109 \\
\hline \multirow[t]{4}{*}{ Logical } & \multirow[t]{2}{*}{ male } & \multirow[t]{2}{*}{$\alpha$} & Lebanese & A & 115.47 & 14.68 & 300 \\
\hline & & & Indian & B & 104.13 & 14.87 & 142 \\
\hline & \multirow{2}{*}{ female } & \multirow[t]{6}{*}{$\beta$} & Lebanese & A & 110.78 & 15.20 & 193 \\
\hline & & & Indian & B & 106.19 & 17.99 & 109 \\
\hline \multirow[t]{4}{*}{ Spatial } & \multirow[t]{2}{*}{ male } & & Lebanese & A & 114.30 & 15.72 & 298 \\
\hline & & & Indian & B & 108.56 & 15.51 & 142 \\
\hline & \multirow[t]{2}{*}{ female } & & Lebanese & A & 113.78 & 13.37 & 189 \\
\hline & & & Indian & B & 108.53 & 16.96 & 109 \\
\hline \multirow{4}{*}{ Musical } & \multirow{2}{*}{ male } & & Lebanese & & 98.84 & 23.33 & 298 \\
\hline & & & Indian & & 100.60 & 20.36 & 142 \\
\hline & \multirow[t]{2}{*}{ female } & & Lebanese & & 100.82 & 21.20 & 190 \\
\hline & & & Indian & & 102.20 & 17.42 & 109 \\
\hline \multirow[t]{4}{*}{ Body Kinesthetic } & \multirow[t]{2}{*}{ male } & \multirow[t]{2}{*}{$\alpha$} & Lebanese & & 112.35 & 16.05 & 292 \\
\hline & & & Indian & & 109.19 & 17.07 & 142 \\
\hline & \multirow[t]{2}{*}{ female } & \multirow[t]{6}{*}{$\beta$} & Lebanese & & 108.25 & 16.24 & 188 \\
\hline & & & Indian & & 107.92 & 20.51 & 108 \\
\hline \multirow[t]{4}{*}{ Inter-personal } & \multirow[t]{2}{*}{ male } & & Lebanese & & 118.42 & 14.70 & 294 \\
\hline & & & Indian & & 120.99 & 100.81 & 142 \\
\hline & \multirow[t]{2}{*}{ female } & & Lebanese & & 122.95 & 12.44 & 189 \\
\hline & & & Indian & & 116.74 & 15.60 & 109 \\
\hline \multirow[t]{4}{*}{ Intra-personal } & \multirow[t]{2}{*}{ male } & & Lebanese & & 117.54 & 14.44 & 293 \\
\hline & & & Indian & & 113.56 & 16.13 & 142 \\
\hline & \multirow[t]{2}{*}{ female } & & Lebanese & & 119.87 & 13.88 & 188 \\
\hline & & & Indian & & 127.29 & 114.31 & 109 \\
\hline Existential & male & & Lebanese & & 114.69 & 17.44 & 289 \\
\hline & & & Indian & & 111.90 & 16.39 & 142 \\
\hline & female & & Lebanese & & 113.96 & 15.55 & 187 \\
\hline & & & Indian & & 113.26 & 17.55 & 109 \\
\hline Spiritual & male & & Lebanese & A & 107.36 & 15.74 & 289 \\
\hline & & & Indian & B & 102.18 & 18.78 & 142 \\
\hline & female & & Lebanese & A & 107.89 & 14.54 & 185 \\
\hline & & & Indian & B & 100.09 & 25.50 & 109 \\
\hline Naturalistic & male & & Lebanese & & 105.77 & 16.76 & 289 \\
\hline & & $\alpha$ & Indian & & 106.30 & 16.46 & 142 \\
\hline & female & & Lebanese & & 105.30 & 16.63 & 185 \\
\hline & & $\beta$ & Indian & & 100.55 & 22.46 & 109 \\
\hline
\end{tabular}

Note: Scores with a different Greek letter indicates significant differences between males and females. A different Latin letter in indicates significant differences between nationalities.

Table 3: F- ratios for the ANOVA of sex by nationality on each of gardner's 10 multiple intelligences

\begin{tabular}{llll}
\hline & Sex & Nationality & $\begin{array}{l}\text { Sex by } \\
\text { Nationality }\end{array}$ \\
\hline Verbal & $20.13^{* *}$ & $19.99^{* *}$ & .00 \\
Logical & 1.18 & $43.40^{* *}$ & $7.81^{* *}$ \\
Spatial & .05 & $20.74^{* *}$ & .04 \\
Musical & 1.12 & .87 & .01 \\
Body Kinesthetic & $3.97^{*}$ & 1.68 & 1.10 \\
Inter-personal & .00 & .25 & 1.45 \\
Intra-personal & $4.88^{*}$ & .03 & 1.92 \\
Existential & .06 & 1.73 & .62 \\
Spiritual & .30 & $21.03^{* *}$ & .86 \\
Naturalistic & $4.97^{*}$ & 2.28 & 3.57 \\
\hline
\end{tabular}

dimensions appeared. Likewise females had higher estimates on the musical and inter-personal dimension. Post-hoc analysis showed that Indian and Lebanese females had higher estimates of intelligence than their male counterparts on the verbal component. Differences also appeared between male and female students for the
Lebanese sample. Significant Scheffe' post-hoc differences appeared between males and females among the Indian sample on the naturalistic dimension.

Cross-national differences appeared for the verbal, logical, spatial and spiritual components of Gardner's multiple intelligences. Post-hoc analysis found that Lebanese self-estimated intelligence higher than Indian students on the cognitive components of the verbal, logical, spatial as well as the spiritual (religious) component of self-estimates of intelligence. Post-hoc Scheffe' analysis revealed that differences were significant at the $(p<0.01)$ level for the logical dimension and attributable to within Lebanese differences where males self-estimated their intelligence higher than females. In addition male and female Lebanese rated significantly higher than Indian male and females respectively. 


\section{DISCUSSION}

A number of studies have assessed sex differences on the seven multiple intelligences. Furnham ${ }^{[19,37]}$; Furnham and Baguma ${ }^{[27]}$; Furnham et al. ${ }^{[38]}$; Furnham et $a{ }^{[8]}$ they reported significant sex differences between male and female students on spatial dimension. ANOVA results showed that Lebanese students selfestimated their intelligence higher than their female counterparts. However, this was not evident in the Indian sample. Studies by Halpern ${ }^{[15]}$ and Bennett ${ }^{[1]}$ suggested that differences between males and females could be attributed to spatial and logical reasoning. For both Lebanese and Indian samples it was found that females self-estimated verbal ability higher than males. These results are somewhat attuned to the stereotypical hypothesis of Beloff ${ }^{[12]}$ and Rammstedt and Rammsayer ${ }^{[39]}$, which suggested that mental components associated with stereotypical gender attitudes prescribe a specific structure to intelligence that differentiated between male and female estimates of intelligence. The only sex difference for the Indian sample appeared for the verbal component in which females showed higher estimates than males, where males gave a higher estimate on the naturalistic component suggesting that Indian male students actively participate in activities related to sports, farming or other physical activities. Evidence also confirms that strong kinship societies are inclined to favor males over females specifically in abilities that are generally male prescribed. For instance, males made significantly higher estimates on the kinesthetic abilities while females were higher on their intra-personal estimates of intelligence. These results are consistent with the universality of sex differences in the way males and females estimate their intelligence.

There were some systematic differences observed between Lebanese and Indian students. Lebanese students tend to consistently provide higher selfestimates than their Indian counterparts. The significant differences on verbal, logical and spatial components are interesting, as Lebanese rated their intelligence higher than Indians on the cognitive components of intelligence, namely, the verbal, logical and spiritual components. It is acknowledged and found in general that the mathematical abilities of students are higher in Asian countries $^{[40]}$. Perhaps, Lebanese high selfestimates of their intelligence is a result of their schooling, for its rigorous training and extensive preparation for higher education. In fact the Baccalaureate certificate in Lebanon is internationally recognized since students have to go through a set of rigorous tests in mathematics, science, languages, social sciences and humanities. These benchmarks for students may make them exaggerate their own selfperceptions. On the contrary, Indian youth seem to be quite realistic in their assessments, given the competitive system and the hardships they go through in the final stage of schooling. In fact, Indian students do not overestimate an ability in which they are confident of sound knowledge and doing well. It has been noted in earlier studies that students from poorer countries, such as Uganda or Slovakia ${ }^{[41]}$ provided higher self-estimates of intelligence than Western nations. Furnham et $a l^{[8]}$, noted that in developing/poorer nations as it is more difficult to get a university seat or even get accepted in the choice of major, students tend to self-estimate their intelligence close to the national norms.

Given the multi-confessional structure of Lebanon's educational system and the teaching of religion in private Lebanese school $^{[42]}$, Lebanese students gave higher estimates of religious intelligence than Indian youth, unlike their Lebanese counterparts, urban educated Indian youth, particularly Hindus (a predominantly higher percent in the sample) do not routinely practice religion or receive religious instruction in the curriculum ${ }^{[43]}$. In addition, interaction effects were found on the logical dimension showing Lebanese males with the highest estimates of intelligence.

Overall, parents' educational level as a correlate did not show significant association with students' estimates of intelligence. It was expected that high educational level of parents would indicate a high level of self-estimates of intelligence as these students may be more nurtured intellectually and would estimate their intelligence higher than those whose parents' do not have such higher educational levels. It is known that in societies characterized by strong kinship societies, parents play an important role in the education and persuasion of the children to advance in education ${ }^{[31]}$. This was not true here. Perhaps, some other factors such as socio-economic factors of the parent played an even greater role ${ }^{[37]}$ in predicting differences in selfestimates of intelligence. In this perspective, it may be helpful in future research to determine what respondents think of their parents' intelligence by using the level of education as a covariate. The results are also interesting because the Lebanese respondents reported significantly higher mean estimates of their parents' education than the Indian sample did. This might be the main reason why Lebanese students gave higher estimates of intelligence than the Indian sample i.e., higher education of the parent is related to higher self-estimates of the offspring. Possibly the educational disparities are more glaring in India than Lebanon and that may be why Lebanese parents nurture their children into pursuing scholastic subjects that stress academic activities at home and at school. Keeping in mind in India "entrepreneur, business and service class" places value on a college education for their offspring (males and females).

Limitations: Caution must be observed when conducting cross-cultural investigations that compare 
different national groups. Although respondents came from the same age group and were all beginning students at the university, there remain many other free floating (uncontrolled) variables that could have played a role in forfeiting the differences between the samples. Furthermore, the concept of the bell-shaped or the normal curve was an educational process and researchers at both ends must make sure that students understood the basic concepts of central tendency before responding to the questionnaire. However, researchers had no control over students' learning and this might have been an intervening variable that affected students' self-estimates of intelligence.

\section{REFERENCES}

1. Bennett, M., 1996. Men's and women's selfestimates of intelligence. The J. Social Psychol., 136: 411-412.

2. Furnham, A. and R. Rawles, 1995. Sex differences in the estimation of intelligence. J. Social Behav. Person., 10: 741-745.

3. Furnham, A. and R. Rawles, 1999. Correlations between self-estimated and psychometrically measured IQ. J. Social Psychol., 139: 405-410.

4. Hogan, H., 1978. IQ self-estimates of males and females. The J. Social Psychol., 106: 137-138.

5. Gardner, H., 1983. Frames of mind: A theory of multiple intelligences. London: Fontana Press.

6. Gardner, H., 1999. Intelligence reframed. New York: Basic Books.

7. Blyth, T. and H. Gardner, 1990. A school for all intelligences. Educational Leadership, 47: 33-37.

8. Furnham, A., S. Shahidi and B. Baluch, 2002. Sex and culture differences in perceptions of estimated intelligence for self and family: A British and Iranian Comparison. J. Cross-Cultural Studies, 35: 270-285.

9. Anastasi, A., 1958. Differential Psychology. 3rd Edn., New York: Macmillan.

10. Tyler, L.E., 1965. The Psychology of Human Differences. New York: Appleton-Century-Crofts.

11. Maccoby, E.E., 1966. Sex Differences in Intellectual Functioning. In E.E. Maccoby (Ed.) The development of sex differences. Stanford, CA:Stanford Univ. Press.

12. Beloff, H., 1992. Mother, Father and Me; Our IQ. The Psychologist, 5: 309-311.

13. Byrd, M. and B. Stacey, 1993. Bias in IQ perception. The Psychologist, 6: 16.

14. Furnham, A., G. Fong and N. Martin, 1999. Sex and cross-cultural differences in the estimated multi-faceted intelligence quotient score for self, parents and siblings. Personality and Individual Differences, 26: 1025-1034.

15. Halpern, D., 1997. Sex differences in intelligence. Am. Psychologist, 52: 1091-1102.
16. Halpern, D., 1992. Sex Differences in Cognitive Abilities. 2nd Edn.. Hillsdale, NJ: Lawrence Erlbaum.

17. Springer, S.P. and G. Deutsch, 1993. Left Brain, Right Brain. New York: Freeman.

18. Furnham, A. and L. Gasson, 1998. Sex differences in parental estimates of their children's intelligence. Sex Roles, 38: 151-162.

19. Furnham, A., 2000. Thinking about intelligence. The Psychologist, 13: 510-515.

20. Furnham, A. and N. Mkhize, 2003. Zulu Mothers' beliefs about their own and their children's intelligence. J. Social Psychol., 143: 83-94.

21. Favia, L. and A. Fontane, 1997. Adolescents' personal conceptions of intelligence. Eur. J. Psychol. Edu., 12: 51-62.

22. Sternberg, R., 1990. Metaphors of Mind: Conceptions of the Nature of Intelligence. New York: Cambridge University Press.

23. Wober, M., 1973. East African undergraduates' attitudes concerning the concept of intelligence. Br. J. Soc. Clin. Develop., 12: 431-432.

24. Keehn, J. and E. Prothero, 1958. The meaning of intelligence to Lebanese teachers. Br. J. Edu. Psychol., 58: 339-342.

25. Azuma, H. and K. Kashiwagi, 1987. Descriptors for an intelligent person: A Japanese study. Jap. Psychol. Res., 29: 17-26.

26. Serpell, R., 1984. Research on cognitive development in Sub-Saharan Africa. Intl. J. Behav. Develop., 7: 111-127.

27. Furnham, A. and P. Baguma, 1999. A crosscultural study from three countries of self-estimates of intelligence. North Am. J. Psychol., 1: 69-78.

28. Furnham, A., T. Hosoe and T. Tang, 2001. Male hubris and female humility? A cross-cultural study of ratings of self, parental and siblings multiple intelligence in America, Britian and Japan. Intelligence, 30: 101-115.

29. Salibi, K., 1990. A House of Many Mansions: The History of Lebanon Reconsidered. Berkeley: University of California Press.

30. Sharma, S., 2002. Development and Democracy in India. Lynne Rienner, Boulder, CO.

31. Khalaf, S., 2001. Cultural Resistance: Global and Local Encounters in the Middle East. London: Saqi Books.

32. Sharabi, H., 1975. Mukadmat Li-Drasat DlMujtam'a Al-Arabi (Introduction to studies of the Arab world). Beirut: Dar Altali'a Liltiba'a Wa'anasher. [In Arabic].

33. Sharabi, H., 1988. Neopatriarchy: A theory of distorted change in Arab society. New York: Oxford University Press. 
34. Sopher, D., 1980. The Geographies of Culture in India. In D.E. Sopher (Ed.), An Exploration of India, pp: 289-326. Ithaca: Cornell University Press.

35. Schvaneveldt, P., J. Kerpelman and J. Schvaneveldt, 2005. Generational and cultural changes in family life in the United Arab Emirates. A comparison of mothers's and daughters. J. Comp. Family Studies, 36: 77-91.

36. Malhotra, A., R. Vanneman and S. Kishor, 1995. Fertility, dimensions of patriarchy and development in India. Population and Development Review, 21: 281-305.

37. Furnham, A., 2001. Self-estimates of intelligence. Personality and Individual Differences, 31: 13811405.

38. Furnham, A., K. Clark and K. Bailey, 1999. Sex differences in estimates of multiple intelligences. Eur. J. Person., 13: 247-259.

39. Rammstedt, B. and E. Rammsayer, 2000. Sex differences in self-estimates of different aspects of intelligence. Personality and Individual Difference, 20: 869-880.
40. Azuma, H., 1998. Japanese Collectivism and Education. In S.G. Paris and H. M.Wellman (Eds.), Global prospects for education: Development, culture and schooling. New York: American Psychological Association.

41. Furnham, A., T. Rakow, I. Sarmany-Schiller and F. De Fruyt, 1999. European differences in selfperceived multiple intelligences. Eur. Psychol., 4: 131-138.

42. Abouchedid, K., 1997. Confessional pluralism and education: Themes from the Lebanese experience. Unpublished Ph.D. Thesis. University of Manchester.

43. Yadav, S., 2006. Implementation of Ten-Year School Curriculum in the States in India: A Study Report National Council of Educational Research and Training, New Delhi, India Available at: http://www.ncert.nic.in/sites/Variables/10\%20Yrs $\% 20$ Sch\%20Curri_final.pdf 